\title{
COVID-19-related patient discrimination by healthcare workers: A single-center experience
}

\author{
Akinwumi Ayodeji Akinbodewa ${ }^{1}$, Oluwole Olugbenga Ige ${ }^{2}$ Michael Olumide Gbala ${ }^{3}$, \\ Gladys Oghenevo Akinbodewa ${ }^{4}$
}

From ${ }^{1}$ Kidney Care Centre, Department of Medicine, ${ }^{2}$ Department of Orthopaedics, ${ }^{3}$ Department of Obstetrics and Gynaecology, University of Medical Sciences Teaching Hospital, ${ }^{4}$ Department of Bursary, University of Medical Sciences, Ondo State, Nigeria

Correspondence to: Dr. Akinwumi Ayodeji Akinbodewa, Department of Medicine, Kidney Care Centre, University of Medical Sciences Teaching Hospital, PMB 542, Ondo City, Ondo State, Nigeria. E-mail: ayoakinbodewa@yahoo.com

Received - 29 March 2020

Initial Review - 13 April 2020

Accepted - 14 May 2020

\begin{abstract}
Discrimination against patients, especially high-risk infectious cases, has been documented in many health-care facilities in Nigeria and abroad. This often results in suboptimal care and undesirable loss of life among such patients. Previously identified causes of this attitude include poor knowledge of the disease, perceived lack of capacity by hospital management to provide sufficient and appropriate personal protective equipment, and fear of exposure of self, colleagues, friends, and family to the infection. We hereby present three cases of suspected coronavirus disease (COVID)-19 in a tertiary health-care facility in Southwest Nigeria to highlight the risk of untimely death posed to patients with respiratory symptoms from other etiologies during the COVID-19 pandemic, need for early intervention by a senior physician and importance of adequate history taking in managing suspected cases of COVID- 19 .
\end{abstract}

Key words: Coronavirus disease-19, Discrimination, Healthcare workers, $n$ Corona virus, Nigeria

$\mathrm{T}$ The 2019 novel coronavirus (2019-nCoV) disease (later renamed coronavirus disease [COVID]-19) was first reported on December 1, 2019, in Wuhan, Central China [1]. On January 3, 2020, the 2019-nCoV was identified in samples of bronchoalveolar lavage fluid from a patient in Wuhan and was confirmed as the cause of the novel coronavirus-infected pneumonia [2]. This novel virus shares $79.5 \%$ of the genetic sequence with severe acute respiratory syndrome (SARS)-CoV and has $96.2 \%$ homology to a bat coronavirus [3]. Since then, it has spread to at least 170 nations.

On March 11, 2020, the World Health Organization declared the SARS-CoV-2 outbreak a pandemic due to the constantly increasing incidence outside China [4]. The first case in Nigeria was reported in an Italian male on February 28, 2020. Barely 6 weeks after the first case, 318 cases have been confirmed across 19 States in Nigeria and Abuja, the Federal Capital Territory [5]. There have been 70 discharges $(22.0 \%)$ and ten deaths (3.1\%). Two of the cases have been confirmed in Ondo State [5].

The Centre for Disease Control has published guidelines for healthcare workers to aid them in identifying people who are most likely to have COVID-19. Regardless of this, there exists widespread panic among healthcare workers. This is of major concern as it could lead to an inadequate clinical assessment by doctors and nurses thus resulting in a "hurried diagnosis of COVID-19" among patients with respiratory symptoms from other etiologies, consequent avoidance of such patients, refusal to offer otherwise required care and in some cases, unwarranted mortality. Patient avoidance and refusal to offer care owing to fear of contracting infection have been previously reported among healthcare workers during the eras of Human immunodeficiency virus/acquired immunodeficiency viral and Ebola viral diseases (EVD), respectively [6,7]. Here, we present three cases that were confused for COVID-19 in a tertiary hospital in Ondo State, Nigeria, and management challenges.

\section{Case 1}

A 40-year-old farmer presented to the accident and emergency department at about 7:30 am of April 5, 2020, with complaints of fever ( 3 days) and acute dyspnoea (about $12 \mathrm{~h}$ ) in association with cough, chest tightness, and excessive sweating. There was no loss of consciousness. Her temperature was $38.2^{\circ} \mathrm{C}$, respiratory rate 40 breaths per minute with wheezes on auscultation. A provisional diagnosis of COVID-19 was made with adult-onset asthma considered as a differential diagnosis. She was placed on intranasal oxygen.

Our team was involved in the case when we took over from the Medical Officer on duty. A review of the patient's record showed deficiencies in history-taking, examination, and management. Her vital signs had not been checked, blood samples were not drawn for the baseline tests, and a chest $\mathrm{X}$-ray was not ordered. Even though IV access was initiated, intravenous drugs ordered by the casualty officer were not administered; the reason being fear of the emergency room 
staff in making contact with the patient despite the availability of protective personal equipment.

We took history in accordance with guidelines for COVID-19 case definitions. It turned out that there was nothing that connected her epidemiologically to COVID-19. Importantly, 6 weeks earlier, she had registered with a secondary healthcare facility on account of recurrent cough. In line with our local policy for COVID-19, the consultant conducted a patient examination. By this time (10:45 am), she was semi-conscious, dyspnoeic, and diaphoretic. Her respiratory rate had reduced to $26 /$ min (prolonged inspiratory phase) with polyphonic wheezes in all the lung fields. The diagnosis was changed to life-threatening acute severe asthma.

Samples were drawn for full blood count, thick and thin blood film for malaria parasite, and serum chemistry. Statum doses of IV hydrocortisone $200 \mathrm{mg}$ and aminophylline $250 \mathrm{mg}$ were administered. Maintenance nebulized salbutamol 5 ug four hourly, IV hydrocortisone $200 \mathrm{mg}$ six hourly, and hourly charting of vital signs were ordered. Laboratory results showed trophozoites of Plasmodium falciparum, leukocytosis $\left(31,000 \mathrm{cells} / \mathrm{mm}^{3}\right)$, and neutrophilia (84\%). The serum creatinine, urea, and bicarbonate were $150.4 \mathrm{umol} / \mathrm{L}, 5.8 \mathrm{mmol} / \mathrm{L}$, and $28.6 \mathrm{mmol} / \mathrm{L}$, respectively. The patient died after $12 \mathrm{~h}$ on April 05, 2020, before the chest $\mathrm{X}$-ray could be done. The nasopharyngeal swab test result for SARS-Cov-2 was negative.

\section{Case 2}

A 22-year-old patient presented at the antenatal clinic on April 6, 2020 , at 28 weeks gestation to the obstetrics emergency room with complaints of productive cough and sore throat (1 week), generalized musculoskeletal pain, headache, and fever of $24 \mathrm{~h}$ duration. She was reviewed by the senior registrar within $30 \mathrm{~min}$. There was no history of recent travel to a country or state in Nigeria with COVID-19. There was no history of contact with suspected or confirmed cases of COVID-19. Her respiratory rate was reported as $40 / \mathrm{min}$, but the temperature was $36.8^{\circ} \mathrm{C}$. A diagnosis of upper respiratory tract infection was made. Differentials were malaria fever and COVID-19 in that order.

A review by the consultant showed that the patient was clinically stable with no evidence of respiratory distress. However, since she was being considered for COVID-19, the managing team decided on isolating her in the designated room, but this was resisted by the head of nurses who claimed that "I will not expose my nurses to undue risk of contracting COVID-19." The hospital infection prevention and control (IPC) team was invited to advise on the next line of action at this point. After reviewing her record, the patient did not fit into any of the case definitions for COVID-19.

She was subsequently discharged home on antimalarial medication, erythromycin tabs $500 \mathrm{mg}$ QDS, Vitamin C $100 \mathrm{mg}$, and paracetamol $1 \mathrm{~g}$ TDS. She was adequately educated on self-isolation and monitoring. Her verified phone contact was obtained for real-time monitoring. The patient's symptoms had since improved after 5 days on antimalarial treatment.

\section{Case 3}

A22-year-old known end-stage renal disease patient, who was poorly compliant to treatment due to financial constraint, was admitted. She presented to the adult accident and emergency on April 20, 2020, with vomiting (1 week), cough (1 day), and breathlessness ( 2 h) associated with hemoptysis and chest pain. There was no history of recent travel to the COVID-19 zone as she was just discharged home by the renal unit a few days earlier. Her vital signs were as follows; blood pressure $200 / 155 \mathrm{mmHg}$, respiratory rate $64 / \mathrm{min}$, and $\mathrm{SpO}_{2}$ of $96 \%$. She was seen by the Junior Registrar on call who reviewed over the phone with the most senior physician.

The IPC team became involved when the most senior physician called to press for SARS-CovV-2 test for the patient and isolation, against which the patient protested. An electronic copy of the protocol for managing suspected COVID-19 cases was forwarded to the unit on call when it became obvious during the conversation that they were not abreast of this. The diagnosis was subsequently reviewed to acute pulmonary edema based on a new history of acute reduction in urine output, poor compliance to hemodialysis, and abnormal serum chemistry results; creatinine $-2,919 \mathrm{umol} / \mathrm{L}$, urea $-38.9 \mathrm{mmol} / \mathrm{L}$, bicarbonate $-9.9 \mathrm{mmol} / \mathrm{L}$, and potassium $-4.3 \mathrm{mmol} / \mathrm{L}$. The patient was transferred to the renal team for emergency hemodialysis and related care.

\section{DISCUSSION}

The above cases probably represent what is currently on-going in most public hospitals in Nigeria and abroad. Our medical and nursing staff were generally unwilling to go near suspected cases for fear of contracting COVID-19. Similar scenarios have been reported previously as shown in a survey of 245 pediatric healthcare workers where only $80 \%$ of participants were willing to examine EVD patients and a further depleted proportion (64-79\%) would go-ahead to perform procedures on them [8]. This attitude correlated with poor knowledge of EVD among the staff [8]. As a matter of fact, on the admission of the first Ebola patient in New York, a large number of the medical personnel called in sick; one of the nurses even pretended she had a stroke and there were some who even believed it was ethical to refuse care of such patients [8-10].

In our experience, even when adequate clinical evaluation pointed to other diseases as the cause of respiratory symptoms, the personnel was reluctant to go near the patients. They gave excuses such as inadequate provisions made by the hospital management for the isolation and care of suspected cases among others. A similar report was documented in a study in the United States of America, where less than half of the participants believed that their institution was well equipped to take care of patients with Ebola [7]. Filippo Anelli, President of Italy's National Federation Order of Surgeons and Dentists, was quoted as saying, "Our doctors have been sent to war unarmed; it is reasonable to assume that these events would have been largely avoidable if health workers had been correctly informed and equipped with sufficient personal protective equipment which instead continues to be in short supply" [11]. 
Fear of contracting the disease was another contributory factor to the behavior of healthcare workers in our setting. This is probably further heightened by reports of COVID-19related deaths among healthcare workers within and outside Nigeria $[11,12]$. For instance, Italy has lost more than a hundred doctors and other healthcare workers (mean age, 80 years) to COVID-19 so far [11].

In our study, we observed that early intervention by a senior physician improved the adequacy of medical history and adherence to guidelines for the COVID-19 case definition resulting in better diagnostic accuracy, level of care, and outcome for the patients. History taking should also be tailored toward identifying other causes of respiratory symptoms, particularly recurrent ones. The senior physician's administrative capacity enables him/her to interact with the management of other hospitals in search of relevant information so as to exclude previously diagnosed chronic (recurrent) respiratory illnesses such as asthma and chronic obstructive lung disease.

Adherence to Universal Basic Precautions should be routine practice for healthcare workers, COVID-19, or not. For instance, in one case report, forty-one healthcare workers were exposed to aerosol-generating procedures (endotracheal intubation, non-invasive ventilation, etc.) while caring for a man with community-acquired pneumonia who later tested positive for SARS-Cov-2. Amazingly, none of them contracted the viral infection as they all remained negative for SARSCov-2 after 14 days of surveillance [13]. This was attributed to the routine use of surgical masks, regular hand hygiene, and other standard procedures which protected them from being infected.

\section{CONCLUSION}

While COVID-19 remains a mysterious and scary infection to date, early intervention by an experienced, senior physician as well as adequate application of case definitions during clerking, is useful in ensuring that patients with respiratory symptoms of other etiologies aside COVID-19 are accurately diagnosed and offered unfettered care.

\section{REFERENCES}

1. Wang D, Hu B, Hu C, Zhu F, Liu X, Zhang J, et al. Clinical characteristics of 138 hospitalized patients with 2019 novel coronavirus-infected pneumonia in Wuhan, China. JAMA 2020;323:1061-9.

2. Zhu N, Zhang D, Wang W, Li X, Yang B, Song J, et al. A novel coronavirus from patients with pneumonia in China, 2019. N Engl J Med 2020;382:727-33.

3. Zhou P, Yang XL, Wang XG, Hu B, Zhang L, Zhang W, et al. Discovery of a Novel Coronavirus Associated with the Recent Pneumonia Outbreak in Humans and its Potential Batbatorigin. Available from: https://www.biorxiv.org/ content/10.1101/2020.01.22.914952v2.full.pdf. [Last accessed on 2020 Apr 09]

4. WHO Director-General's Opening Remarks at the Media Briefing on COVID-19; 2020. Available from: https://www.who.int/dg/speeches/detail/ who-director-general-s-opening-remarks-at-themedia-briefing-on-covid19---11-march-2020. [Last accessed 2020 Mar 30].

5. An Update of COVID 19 Outbreak in Nigeria; 2020. Available from: http:// www.covid19.ncdc.gov.ng. [Last accessed on 2020 Apr 10].

6. Bharat S, Aggleton P, Tyrer P. India: HIV and AIDS-Related Discrimination, Stigmatization and Denial. Geneva: Joint United Nations Programme on HIV/ AIDS; 2001. p. 16-7. Available from: http://www.data.unaids.org/Publications/ IRC-pub02/JC587-India_en.pdf. [Last accessed on 2020 Apr 09].

7. Narasimhulu DM, Edwards V, Chazotte C, Bhatt D, Weedon J, Minkoff H. Healthcare workers' attitudes toward patients with ebola virus disease in the United States. Open Forum Infect Dis 2016;3:1-7.

8. Highsmith HY, Cruz AT, Guffey D, Minard CG, Starke JR. Ebola knowledge and attitudes among pediatric providers before the first diagnosed case in the United States. Pediatr Infect Dis J 2015;34:901-3.

9. Schram J, Celona L. Bellevue Staffers Call in "Sick" After Ebola Arrives. New York Post; 2014. Available from: http://www.nypost.com/2014/10/25/ manybellevue-staffers-take-sick-day-in-ebola-panic. [Last accessed on 2015 Jun 04].

10. Fox News. Hospital Staffers Reportedly Take Sick Day Rather than Treat New York's First Ebola Patient. Infectious Disease; 2014. Available from: https:// www.foxnews.com/health/hospital-staffers-reportedly-take-sick-day-ratherthan-treat-new-yorks-first-ebola-patient. [Last accessed on $2020 \mathrm{Apr} 10$ ].

11. Chustecka Z. More Than 60 Doctors in Italy have Died in the COVID-19 Pandemic; 2020. Available from: https://www.medscape.com/ viewarticle/927753. [Last accessed on 2020 Apr 08].

12. Nigerian Doctor Dies of Corona Virus. Agency Reports. Available from: https://www.premiumtimesng.com/news/headlines/386543-nigeriandoctor-dies-of-coronavirus.html. [Last accessed on 2020 Apr 11].

13. Ng K, Poon BH, Kiat Puar TH, Quah JL, Loh WJ, Wong YJ, et al. COVID-19 and the risk to healthcare workers: A case report. Ann Intern Med 2020; https://doi.org/10.7326/L20-0175.

Funding: None; Conflicts of Interest: None Stated.

How to cite this article: Akinbodewa AA, Ige OO, Gbala MO, Akinbodewa GO. COVID-19-related patient discrimination by healthcare workers: A single-center experience. Indian J Case Reports. 2020;6(5):224-226.

Doi: 10.32677/IJCR.2020.v06.i05.002 